\title{
The Problems and Approaches to Educational Planning in Nigeria: A Theoretical Observation
}

\author{
Nwachukwu Prince Ololube \\ Department of Educational Foundations and Management \\ Ignatius Ajuru University of Education, Port Harcourt, Nigeria
}

\section{Doi:10.5901/mjss.2013.v4n12p37}

\begin{abstract}
The Nigerian educational system has undoubtedly encountered a number of significant impediments in the last few decades and it continue to struggle with the implementation and assurance of educational and teaching quality because of lack of effective planning. A shortage of accurate statistical data, financial, qualified planners, poor national economic performance, unsuitable governing structures, political interference, and general instability have all contributed to low quality in educational planning. This paper looks at the meaning and context of educational planning and the planning process. The paper concludes that in spite of the increasing complexity of schools created by rising enrollments and problems of research, programs of study must be tailored to the ever-more complex needs of the society. Schools are established for the improvement of society and thus, socioeconomic planners and educational planners need to cooperate in planning for the benefit of both the school and society.
\end{abstract}

Keywords: Educational planning, Planning process, Problems, Approaches, Schools, Nigeria

\section{Introduction}

A very remarkable problem that has tended to inhibit educational production especially in Nigeria over the years is lack of human and material resources. In general, the major problems affecting the school system in Nigeria are poor management and control of teacher education programs, teacher training and retraining, the selection and organization of curriculum content, curriculum implementation and evaluation, the development, distribution and use of teaching materials, and the relevance of the curriculum to the needs of society. Not surprisingly, there is also a problem with poor motivation and discipline (Adeniyi, 2001, pp. 7-11). Educational production is the determination of schooling quality as reflected in students' educational performance (see Bishop and Wößmann 2001). They went further to argue that the parameters which influence the level of schooling quality achieved in the model of educational production are mainly driven by the institutional setting in the schooling system (p. 15).

Scholars like Adeniyi (2001), Nwabueze (1995) and Agi and Adiele (2009) have discussed in their respective works the crises and problems facing education in Nigeria. These problems are not peculiar to developing countries; schools in developed countries still compete for public funds with other sectors of the economy. Educational objectives can be achieved when resources are made available and put into maximum use. Educational planning, human resources (HR) training and development have evolved as disciplines to guide the allocation and utilization of educational resources in the school system. This is required to arrest areas of waste of resources to make educational production more effective. In this regard, educational planning, HR training and development have become indispensable tools in the management of the school system in order to achieve the desired goals of education systems around the world.

The output of the planning process is the plan itself, which is a blueprint for action. It prescribes the activities needed for the education industry to realize its goals. Therefore, the purpose of planning is simply to 
ensure that the educational industry is effective in its activities. In a broader sense, an educational system must develop a plan that ensures that the appropriate products and services are offered to its students. More specifically, planning gives guidance and direction to members of an organization as to their role in delivering the products and services (Peretomode 1991, 1995; Naylor 1999).

A wise person who has enough money to build a house must necessarily make some initial decisions prior to the actual building of the desired house. In the first place, he may decide on the area or site of his interest and find out ways of representing the proposed building on paper for approval by experts. He may need to consult other experts to estimate the cost of the building so that he will know how much money will be required at each stage of the work. This is planning in action: planning is the process of determining a scheme for accomplishing a purpose. Such a scheme of arrangement is to be made beforehand by preparing a purposeful method of achieving the desired objectives (Whawo, 1993, p. 106). According to Musaazi (1982), planning is a rational process of preparing and coordinating a set of economic decision making for future actions directed at achieving objectives by optimal means. Admittedly, planning is a guide to the actions that are to be implemented at a future date. In other words, planning is futuristic. The rationale for planning is to effectively utilize available resources to attain a predetermined objective. The process involves strategies for manipulating several variables at the time of planning and their projection into the future.

Therefore, in the words of Coombs (1972) and Ololube (2009), educational planning in its broadest generic sense is the application of rational, systematic analysis to the process of educational development with the aim of making education more effective and efficient in responding to the needs and goals of its students and society. The principal focus of educational planning in this definition is to make education more result-oriented for the development of the individual and the larger society. As Adesina (1981) pointed out that educational planning is the process of applying scientific or rational procedures to the process of educational growth and development so as to ensure the efficiency and effectiveness of the educational system through a planning mechanism (see the Figure 1 for planning mechanism). In the planning mechanism, once feasibility of the proposed service had been established a number of specific actions were necessary in order to ensure that an operational service could become a reality (Robertson, 1991).

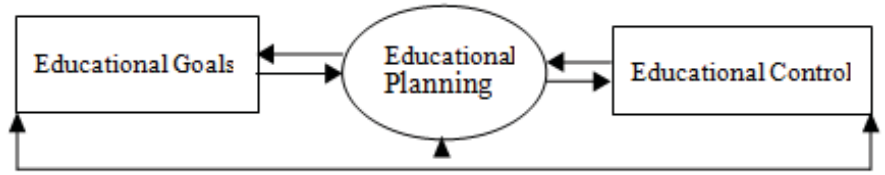

Figure 1: Planning Mechanism. Adapted from Ololube, N. P. (2013)

\subsection{Planning Process}

The aforementioned characterizations suggest that educational planning is a "process" as depicted in the Figure 2. This means that the outline of activities to be done is drawn up and sequentially arranged for implementation. A plan is described as efficient if the resources put into it are sufficient in meeting the stated objectives. An effective plan is one in which the desired objectives have been achieved. It is essential for educational production to be both efficient and effective if it is to properly guide the internal changes in the school as it utilizes the educational resources available. In other words, educational planning provides a foundation for all educational activities (Ololube, 2006a,b). It is the process of outlining the activities that are necessary to achieve the goals of education. Through planning, educational planners determine how education resources are to be allocated and how the activities of the education system will be assigned to individuals and work groups. Therefore, educational planning is a concise and deliberate attempt, through organized and continuous processes to identify the different elements and aspects of the educational industry. It helps us in determining the present state and interaction, hence projecting them throughout a 
given period of time. This is done by analyzing, formulating, implementing and controlling the actions that have evolved to attain the desired aims and objectives of education (Ololube, 2013). This leads us to focus on enhancing the competitive position and the overall performance of teachers through strategic planning.

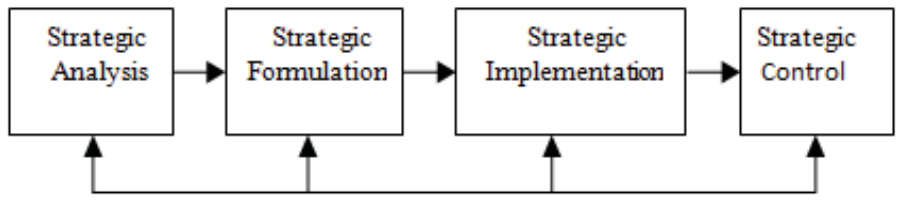

Figure 2: Feedback Process. Adapted from Ololube, N. P. (2013)

The history of strategic planning began in the military. According to Webster's New World Dictionary, strategy is "the science of planning and directing large-scale military operations, of manoeuvring forces into the most advantageous position prior to actual engagement with the enemy". Although our understanding of strategy as applied in management has been transformed, one element remains prominent: the aim to achieve competitive advantage. Taking its name and roots from the military model, early formal strategic planning "reflected the hierarchical values and linear systems of traditional organizations, undertaken by elite planning function at the top of the organization, its structure was highly vertical and time-bound. A certain period would be set aside to analyze the situation and decide on a course of action. This would result in a formal document; once this was done the actual work of implementation - which was considered a separate, discrete process - could begin" (Wall \& Wall, 1995). Although individual definitions of strategy vary between authors, traditionally, theorists have considered planning an essential part of organizational strategy (Ololube, 2009). Educational strategic planning is the process by which the education industry makes decisions and takes action that affects its long-term performance. It is an output of the planning process. It defines both the teachers in the education system and the students in relation to the teaching and learning process. At this point let us briefly take a glance at the various components of the strategic planning process. The feedback process is a mechanism in which educational institutions may need to cycle back to a previous stage in the planning process thereby creating room for adjustments if need be.

\subsubsection{Strategic Analysis}

This is the first stage of the strategic planning process; it aims at evaluating the present condition of the education system. That is, it requires a thorough evaluation of the system's internal operation. The purpose of internal/external analysis is to identify the educational system assets, skills, and resources that represent strengths, weaknesses, obstacles and challenges (SWOT). Strengths are favorable internal characteristics that the educational system can apply to achieve its strategic goals. Weaknesses are internal characteristics that hinder or limit goal accomplishment. Obstacles are features of the environment that will cause the educational system not to realize its goals if it cannot resist or avoid them. Challenges are features of the environment that favor the educational system provided it is able to take advantage of them (Naylor, 1999, pp. 313-316). The focus here is that analysis looks at the current position of the educational system. The underlying idea here is that an application of SWOT into Nigeria's education system will go a long way in solving the ever-complex strategic management scenario facing educational administrators instead of scavenging for thoughts.

SWOT Analysis is a simple framework for generating alternatives from situation analysis. It is applicable to either the corporate level or business unit level and frequently appears in marketing plans. SWOT (sometimes referred to as TOWS) stands for Strength, Weakness, Opportunities and Threats. The SWOT framework was described in the late 1960's by Edmund P. Learned, C. Roland Christiansen, Kenneth 
Andrews, and William D. Guth in Business Policy, Text and Cases (1969). The General Electric Growth Council used this form of analysis in the 1980's because it concentrates on the issues that could potentially have the most impact; the SWOT analysis is useful when a very limited amount of time is available to address a complex strategic situation (ICMBA, 2004). The Figure below shows how a SWOT analysis fits into the strategic analysis of education.

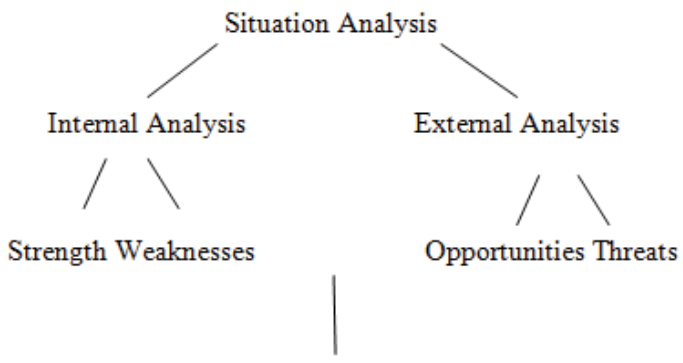

AWOT Profile

Figure 3: SWOT Analysis. Source: Internet Center for Management and Business Administration (2004).

Lerner maintained that SWOT analysis identifies factors that may affect desired future outcomes of education. The SWOT model is based on identifying the education industry's internal strengths and weaknesses, threats and opportunities of the external environment, and consequentially identifying the educational industry's distinctive competencies and key success factors. These, along with considerations of societal and educational values lead to creation, evaluation and choice of strategy. SWOT's objective is to recommend strategies that ensure the best alignment between the external environment and internal situation (Lerner, 1999).

The internal and external situation analysis can produce a large amount of information, much of which may not be relevant. The SWOT analysis can serve as an interpretative filter to reduce the information to a manageable quantity. SWOT analysis classifies the internal aspect of the company as strengths or weaknesses and the external situational factors as opportunities or threats. Strengths can serve as a foundation for building a competitive advantage while weaknesses may hinder it. By understanding these four aspects of its situation, a firm can better leverage its strengths, correct its weaknesses, capitalize on golden opportunities, and deter potentially devastating threats (ICMBA, 2004).

\subsubsection{Strategic Formulation}

If the strategic analysis is completed and the current position of the educational system is ascertained, the next step is to look at where the educational system wants to be. It now follows that the mission of the educational system (the rationale for which the education system exists) has to be established. It involves setting strategic goals (the results that the educational system seeks to achieve in the long-term), identifying strategic alternatives as well as evaluating and choosing the strategy that provides the optimum performance of the educational industry in a long term. This idea is in line with what ICMBA (2004) opined when they asserted that "once a clear picture of the firm and its environment is in mind, specific strategic alternatives can be developed. While different firms have different alternatives depending on their situation, there also exist generic strategies that can be applied across a wide range of firms". ICMBA cited Michael Porter who identified cost leadership, differentiation, and focus as three generic strategies that may be considered when defining strategic alternatives. Porter advised against implementing a combination of these strategies for a given product instead arguing that only one of the generic strategy alternatives should be pursued. 


\subsubsection{Strategic Implementation}

After strategic formulation comes the implementation stage. The best-formulated strategy is useless or rather worthless if it cannot be implemented effectively. If the educational industry is to achieve the best result for which it was established through its strategic planning efforts, it must make sure that its strategy is put into action. The underlying idea here is ascertaining how the education system can get to where it wants to be. The strategic planning process is the critical stage in the history of Nigerian education: implementation has been inconsistent and statistical deficiencies as well as inadequately skilled personnel inhibit the planning process in most cases. However, if a choice has been made on the strategy to use, according to ICMBA (2004), the strategy likely will be expressed in high-level terms and priorities. For effective implementation, it needs to be translated into more detailed policies that can be understood at the functional level of an educational system. The expression of the strategy in terms of functional policies also serves to highlight any practical issues that might not have been visible at a higher level. For effective implementation of a strategic plan, the policies should be translated as much as possible into specific policies for the functional level line staffs in the school system (academic and non-academic) to understand the purpose for which the plan is carried out.

\subsubsection{Strategic Control}

This is the final stage of the strategic planning process. Strategic control involves the monitoring of the implementation process thereby ensuring that it is in line with the expected performance. An effective education control system identifies problems inherent in the process and alerts the policy/decision makers who then make modifications. The underlying idea here is determining how the educational system will know when it has arrived (Ololube, 2004; 2006b).

The reason education production needs planning is vital at this stage of our discussion since there are several problems that face the school system in Nigeria (Nwabueze, 1995). One such problem is of the rising demand for schooling and thus the increasing number of students enrolled. Brint (1998, pp. 37-38) argues that this rising demand for schooling is necessitated to a significant degree by changes in the kinds of occupations produced by maturing economies. Where once secondary schools prepared elites for higher education and society, now they are, "mass terminal institutions" for white-collar workers and "mass preparatory institutions" for professional-managerial workers-though he allows that occupational change is probably not the most important factor behind the rising demand for schooling.

\section{Problems of Educational Planning in Nigeria}

However nice this might be, educational planning faces many challenges. Some of the problems include:

\subsection{Inaccurate Data}

One of the most difficult challenges that educational planners face is the issues of inaccurate statistical data. The quality of technical planning is in most cases inhibited by statistical deficiencies and inaccurate data. Nigerian education systems has failed to effectively plan because of lack of accurate data, which is because of the use of mediocre to prepare data for use in the planning and forecasting processes.

\subsection{Inadequate Skilled Personnel}

Most educational planners in Nigerian do not have complete competence in planning. Qualified planners are the single most significant resource that can lead to greater and efficient planning productivity and 
performance. In planning, what is needed is the effective utilisation resources by connecting the totality knowledge, skills and talents to achieve planning objectives. The quality of planners should not be nothing les than the basic acceptable standards worldwide.

\subsection{Technological Problem}

Another serious problem in the planning of education in Nigeria is the lack of attention paid to emerging technological innovations planning mechanisms. The success of Nigerian education planners depends upon their ability to identify and respond to technological changes in other to elevate their planning output. Over the years, a number of technological changes have taken place that involves the introduction of modern advancements into the planning process and approaches, and understanding emerging issues related to educational planning and development.

\subsection{Political Arrangement}

The existing political arrangement has influenced the control over educational planning in Nigeria. Political instability have had its toll on educational programmes. Planning process started by one administration is brutally interrupted by the next and the differences between federal and state government education policies are quite challenging. The inability of the Nigerian political structure does not allow for education planners to be accountable for their wrong doings.

\subsection{Economic Circumstances}

The budgetary allocations that are available for educational planning in Nigeria is nothing to write home about. Funds provide for education planning is too small for proper planning to take place. The condition of the sector remains a thing of concern. Under-funding and systemic corruption makes the matter worse. The insufficient funding of the education planning sector stands as one of the major factors working against effective planning and implementation of education programmes.

\subsection{Inadequate Planning}

There is a popular saying that "he or she who has failed to plan has planned to fail". Education planning in Nigeria has always been inadequate in line with the enormous facing our educational system. The lack of effective planning poses a significant obstacle to the advancement of education across the country. The success of any educational system hinges on proper planning. Planning of human and material resources has evolved to guide the allocation and utilisation of educational resources in the school systems. Such planning is required to arrest areas of wasted resources and to make educational production more successful. Consequently, for any educational system to truly develop, effective planning is indispensable as education and planning are essential characteristics for effective education (Ololube, 2013).

\section{Approaches to Educational Planning}

Olambo (1995) identified three basic approaches to educational planning. They are:

1. The social demand approach

2. The human resources requirement approach

3. The cost benefit analysis 


\subsection{The Social Demand Approach}

This approach requires the education authorities to provide schools and find facilities for all students who demand admission and who are qualified to enter school. this approach looks on education, as service demanded by people just like any other social services. Politicians in developing countries often find the approach expedient to use because of its appealing nature. The approach provides planners with the approximate number of places where educational facilities has to be provided. It is as well a suitable political tool to meet the need to satisfy the demands of the general public. In situations where resources are acutely limited, and where we are seeking to provide those kinds and quantities of education, which will offer the greatest good to the greatest number, this planning techniques are best.

\subsection{The Human Resources (HR) Requirement Approach}

The focus of this approach is to forecast the human resources needs of the economy. That is, it stresses output from the educational system to meet the human resources needs at some future date. HR approach could usefully call attention to extreme gaps and imbalances in the education out-put pattern that need remedy and provides educators useful guidance on how roughly educational qualifications of the labor force ought to be developed in the future. That is, the relative proportion of people who would have primary education, secondary education and various amount of post-secondary training. This approach looks at the unemployment and underemployment situations, which may result from some over-emphasis on HR approach may become a challenge to move towards the right kind of education which may be developmentoriented, and thereby creating its own job. The HR approach focuses on 3 main elements, namely:

- Specification of the composition of human resources need at some future date, for example, 20202025.

- Specification of human resources availabilities, for example, in 2013.

- Specification, which reconciles the former specification with the later.

\subsection{Cost-Effective Strategies}

There is no general agreement on the most cost-effective strategies school administrators should use to demonstrate appreciation of school employees. However, the following have been cited by Wali and Elekwa (2012, pp. 190-196) as possible methods or alternatives:

1. Staff awards: staff will appreciate that their activities or actions are noticed and appreciated by their supervisor. For the administrator to achieve this, one option is offering a "behind the scene" award at the end of the year for humble employees who perform well. A teacher whose students excel in his or her subject in public examinations could, for example, be rewarded with such a prize. Similarly a teacher who makes a successful outing with students on an inter-school competition may deserve an award.

2. A surprise achievement celebration: quite simply, this can be achieved by providing a special lunchtime treat to an employee or team of employees whose actions deserve recognition. Alonge in Wali (2002) is of the opinion that administrators who give small gifts for special occasions (birthdays, weddings, etc.) or give free tea, coffee and snacks to their employees also makes them feel appreciated and motivated. In all of these cases it is the act of acknowledging the contributions and value of the employees.

3. Pass on praise: if a school administrator hears or is made aware of a positive remark about a staff person, he/she should repeat it to that employee as soon as possible, perhaps via email or send a thank you note to the employee's home address, copying the Dean and Head of Department. This will show that the administrator understands how much the employee may have sacrificed or given 
to complete their assignment with excellence.

4. Publish a Kudos Column in the school newsletter and ask employees to submit kudos for their peers. Similarly set up a suggestion program by either establishing a suggestion box or completing school-wide questionnaires so that employees feel that their opinions and ideas are taken seriously.

5. Recognize employee value by delegating functions according to levels of competence: Wali (2010) observed that delegation is necessary for an organization like a school to exist and grow. Employees who are neglected in the distribution of functions often become apathetic to the achievement of school goals.

6. Make teaching jobs challenging: School administrators should not allow teachers to stay too long in one assignment. In other words, classes and responsibilities should be rotated. A form master could, for example, rotate with house master and vice versa. School administrators should avoid saddling a willing staff with too many responsibilities, since a heavy work load has been identified as a major source of stress (Nwankwo, 1982).

7. Ensure that existing school policies are not frustrating: obnoxious school policies can be an obstacle to an employee's competence at work. There are, for example, schools where employees must fill out forms or wait for "visiting hours" before seeing their principal. Enyi (2004) notes that unless such rigid bureaucratic arrangements are dismantled and more open systems of administration are adopted, employees will continue to face unnecessary frustration at work.

8. Express interest in your employee's professional development: Teacher training does not end when they begin teaching, but that teaching demands rigorous and continuous training. Employee professional development and training should be seen as a continuum. School administrators should ensure that their employees attend programs that will increase their professional growth and capacity. Even if a school cannot fund professional development opportunities, employees will still appreciate an administrator's interest and guidance in this regard (Ornstein \& Levine, 2006).

\subsubsection{Cost-Benefits Analysis of Education}

The Cost-Benefits Analysistechnique gives a simple, quantitative approach for deciding whether to go ahead with a decision. Cost-effectiveness analysis provides a method of comparing alternatives for their relative costs and results and in this way provides guidelines on which of the alternatives provides the most impact relative to cost (Wali \& Elekwa, 2012). Applying this to the education context, Levin in Ololube (2013) asserts that cost-effectiveness enables measures of learning and other contextually-appropriate indicators to assess educational outcomes relative to costs. Adesina (1981) noted that cost-benefits approach looks at each level of education as investment in human beings with the purpose that the returns will help to improve the whole economy. Assumptions are that the wages and salaries paid to worker reflect differences in productivity. The variations in productivity result from different amount and kind of education people receive. It is a mode of analysis of current relationship between education and income. The benefits of this approach are that by looking at the age earnings structure of the educated person, it is possible to measure or quantify the increase in productivity of an educated person. The analysis can show or suggest the directions in which education systems in a society should expand so as to maximize the earning capacity of their products, and the relationship between the cost of gaining more education and the increase in payment which results from additional education (Olambo, 1995; Wali \& Elekwa, 2012).

\subsubsection{Advantages of Cost-Effective Strategies in Schools}

The first advantage of cost effective strategies is that they are useful to school administrators and other proprietors of schools given the limited and often inadequate resources at their disposal. Cost effectiveness 
strategies can help to make the best use of the resources that are available. Secondly, cost effective strategies are useful where budget allocation or funds to perform certain activities are fixed and administrators are considering alternatives that may use the given level of funds in a new way so to achieve greater benefits or greater effectiveness. Finally, cost effective strategies are useful to school administrators, policy makers and planners in situations where the objectives and benefits of a program and accomplishment are fixed. Cost-effectiveness analyses can enhance and complement national strategies to garner new political commitments and evidence-based action (Hu et al., 2007; Wali \& Elekwa, 2012).

\section{Employee Professional Development/Competencies}

What is professional or job competence? What are the main domains and structure of professional competence? What part of competence can be upgraded by education? The answers to these questions are necessary for trying to find the most successful ways in maintaining and developing professional competence (Kautto-Koivula, 1993, 1996). There are considerable diversities in the terminology used in the study of professional competence. The main reason for this is the early developmental status of the field and the multifaceted nature of the phenomenon being studied. Most of the research work to date has been discipline specific, so the concepts and terminology much reflect the perspective of a given discipline.

Moreover, since there are enormous diversities in the definition of the concept of professional competencies, and in as much as the competency concept is young and in development, the multiplicity of definitions does not mean that various scientific and professional publications do not agree on a single aspect of the competency concept. For example, Kirschner and Thijssen (2005, pp. 70-75) described the competency concept as a cluster of person-related qualities suitable to deal in a fitting manner with a clearly defined problem situation. Their definition includes three competency characteristics where a reasonable level of agreement exists:

- Competency is person-related. People possess different competencies in varying degrees.

- Competency is criteria-related. Different criteria must be defined and used to assess the acquisition of a competency.

- Competency is context-related. A competency can manifest itself in different ways in different contexts as opposed to knowledge, which is context independent.

There has also been an increased argument about whether professional competence is best defined and measured as a one-dimensional concept or a multidimensional concept involving many distinct components. Meanwhile, empirical studies have suggested both models of competence; however, multidimensional models are particularly useful for at least the following reasons:

- As individuals continue in their professions across their work life, their knowledge, skills and abilities become increasingly differentiated and specialized. The wide variety of experiences accrued by mid-career results in the development of competence in various domains.

- A multidimensional approach is useful for identifying those components most in need of updating. It is likely that a mid-career professional's level of competence varies across different skill domains. Therefore, because of a supportive work environment or updating activities, a mid-career professional may remain competent in some dimensions but less competent in others.

- A multidimensional approach is useful in examining how specific factors in the work environment support or limit performance in particular competence domains (Kautto-Koivula, 1993).

Though Eraut (1994, p. 164) trying to distinguish between professional competence claims noted that sometimes this is very general and means little more than being properly qualified, especially in professions where the unqualified are not permitted to practice. For instance, when clients or service users describe a professional as competent they usually mean that they have had nothing detrimental on the grapevine. That means the everyday use of the term professional competence carries some performance referencing, although it may be neither extensive nor specific. 
According to Willis and Dubin (1990, p. 3) professional competence involves the ability to function effectively in the tasks considered essential within a given profession - in comparison to job competence that is more concentrated to a specific organization and job. Professional competence is reflected in the performance of the professional, and observing the professional's performance accesses the level of competence. An important outcome of the maintenance of competence is professional vitality which involves the ability to meet successfully the forth-coming challenges.

To Kautto-Koivula (1996, p. 154) professional competence is often considered to involve at least two main domains: (1) proficiencies specific to the profession, discipline or organization. These include the discipline-specific knowledge-base, technical skills considered essential in the profession, and the ability to solve the type of problems encountered within the profession, and (2) general characteristics of the individual that facilitate the individual's development and maintenance of professional competence; these are intellectual ability, personality traits, motivation, attitudes and values. She further distinguished three cognitive domains of competence: (1) skills (either manual or intellectual); (2) knowledge which is simply information committed to memory, and (3) the deeper learning variously described as understanding, conceptual learning or meaningful learning.

To Eraut (1994, p. 165), in professions (or specialism within a profession) where work is relatively homogeneous, there will be little confusion between statements of general and specific competence because one can be reliably inferred from the other. However, in professions or specialities where the work is relatively heterogeneous and one profession may handle a completely different set of situations than another, general statements become rather dangerous. Willis and Dubin (1990) made it clear that it is important to differentiate between level of competence and level of productivity, and it is equally presumed that there is a correlation between competence level and production level. However competence cannot be evaluated completely in terms of productivity. Although they argue that competence is necessary for high-level productivity, by itself it is not sufficient. An individual may be highly competent but because of personal or environmental factors, not productive.

Nevertheless researchers like Willis and Dubin (1990); Eraut (1994); Kautto-Koivula (1993, 1996); Leino (1996) and Kirschner and Thijssen (2005) recognized that a network of colleagues or experts (professional associations) is an important tool in broadening the competence of individual professionals. It is clear therefore that this factor is very relevant to professional competence. Likewise it is important to note that individual professional experience and personal characteristics as parts of high professional competence should not be undermined. The relationships and importance of different competence factors are very much dependent on the job and further profession requirements. By whatever means, there is a strong case for professional development according to OECD (1998). They concluded that for professional competence to flourish, there must be greater collaboration between individuals, schools, universities, and society at large.

\section{Conclusion}

As enrollment in schools increases daily, the available resources may become over-stressed. The situation becomes even more frightening when a universal education program in Nigeria is been implemented. Therefore, adequate planning of the human and material resources is needed to address the issue of everincreasing enrollment and the need to provide them with teachers who can help them achieve appropriate educational objectives. Additionally, the rising cost of education leaves some schools with low quality and inadequate material and human resources. This is because there is no cheap education the world over. Thus, the need for alternative ways of utilizing slim resources to attain set objectives makes planning imperative. The complexity of schooling, its constraints, contingencies, and other difficulties also make planning a necessity. The scarce resources in schools may be wasted if their utilization is not properly planned.

According to Meyer (1998), the rapidly increasing school enrollments around the world, in industrial and 
non-industrial societies alike, cannot simply be explained by occupational changes. At any given level in the schooling process an S-shaped enrollment curve can be traced. At first enrollments increased slowly. When they reach a "tripping point", however, they rapidly level off once near-universal enrollment has been achieved. Thus, even more important than occupation change has been changing expectations about how much schooling is "enough." Some families may begin to see schooling as providing important social benefits, such as the prospect of mixing with a higher class of people while others may see it as providing possible opportunities for economic advancement. These families will pursue strategies that allow them to invest more heavily in schooling.

Despite the increasing complexity of schools created by rising enrollments and problems of research, programs of study must be tailored to the ever-more complex needs of the society. Schools are established for the improvement of society and thus, socio-economic planners and educational planners need to cooperate in planning for the benefit of both the school and society.

\subsection{Future Trends}

The need to plan for quality education reform in any nation cannot be over-emphasized. When reform is adequately planned, it accelerates structural integration of a plural society by equalizing economic, social and political opportunities (Alabi \& Okemakinde, 2010). Thus, educational planning is concerned with the problems of how to make the best use of limited resources allocated to education in view of the priorities given to different stages of education or different sector of education and the need of the economy (Olambo, 1995; Ololube, 2013).

This theoretical study suggests several propositions for future research and practice. These inferences pertain most directly to students, researchers, faculty and higher education institutions. At the management level in education, this study calls for policies to ensure balanced investments in, and increased funding for, education planning that will allow for the effective use, integration and diffusion of educational planning services and methods in the teaching and learning processes. As with other theoretical studies, the observation $n$ this study should not be regarded as definitive but as offering students, faculty, educators, researchers, planners and administrators a view of the author's reality on the use of educational planning in a developing economy.

\section{References}

Adeniyi, E. O. (2001). The Situation in Nigeria; the Problem of Nigeria Educational System. In Pillai, R. (Ed). Strategies for Introducing New Curricula in West Africa. Final Report of the Seminar/Workshop held in Lagos, Nigeria, 12-16 November 2001.

Adesina, S. (1981). What is Educational planning? Introduction to Educational Planning. Ili-Ife; University of Ife Press.

Agi, U. K., \& Adiele, E. E. (2009). Educational Management. Port Harcourt, Nigeria: Rodi Printing and Publishing.

Alabi, A. O., \& Okemakinde, T. (2010). Effective Planning as a Factor of Educational Reform and Innovation in Nigeria. Current Research Journal of Social Sciences 2(6), 316-321.

Bishop, J. H. \& Wößmann, L. (2001). Institutional Effects in a Simple Model of Educational Production. Kiel Working Paper No. 1085.

Coombs P. H. (1972). What is Educational Planning? Paris: UNESCO IIEP.

Enyi D. (2004). The Administrative Process. In T. O. Mgbodile (ed.). Fundamentals in educational administration and planning. Enugu, Magnet.

Eraut, M. (1994). Development Professional Knowledge and Competence. London: Falmer Press.

Hu, D., Bertozzi, S. M., Gakidou, E., Sweet, S., Goldie, S. J. (2007). The Costs, Benefits, and Cost-Effectiveness of Interventions to Reduce Maternal Morbidity and Mortality in Mexico. PLoS ONE 2(8): e750. doi:10.1371/journal.pone.0000750

ICMBA (2004). SWOT Analysis. Journal of Internet Center for Management and Business Administration. Retrieved June 20, 2013 from http://www.netmba.com/strategy/swot/ 
Kautto-Koivula, K. (1993). Degree-Oriented Professional Adult Education in the Work Environment. A Case Study of the Mian Determinants in the management of a Long-term Technology Education Process. Unpublished PhD dissertation, University of Tampere, Finland.

Kautto-Koivula, K. (1996). Degree-Oriented Adult Education in the Work Environment. In Ruohotie, P., \& Grimmett, P. P. (Eds) Professional Growth and Development: Direction, Delivery and Dilemmas. (pp. 149-188). Canada and Finland: Career Education Books.

Kirschner, P. A., \& Thijssen, J. (2005). Competency Development and Employability. LL in E longlife Learning in Europe, $X(2), 70-75$.

Lerner, A. L. (1999). A Strategic Planning Primer for Higher Education. Brief History of Strategic Planning. Retrieved June 20, 2013 from http://www.des.calstate.edu/strategic.html

Meyer, T. (1998). The Definition and Scope of Human Resource Management Standards Generating Body: Human Resources Management \& Practices (SGB: HRMP) Approved at a plenary meeting of stakeholders on 27 September 1999. Retrieved June 16, 2013 from http://www.hrsgb.org.za/HR_scope_and_definition.html

Musaazi, J. C. S. (1982). The Theory and Practice of Educational Administration. London: Macmillan Press.

Naylor, J. (1999). Management. Harlow, England: Prentice Hall.

Nwabueze, B. O. (1995). Crises and Problems in Education in Nigeria. Ibadan: Spectrum Books.

Nwankwo, J. I. (1982). Educational administration: Theory and Practice. New Delhi, India: Viklas.

OECD (1998) Staying Ahead: In-service Training and Teacher Professional Development. Paris: OECD.

Olambo, F. F. (1995). Approaches to Educational Planning. Retrieved June 14, 2013 from http://neocgroup.com/atesui.com/Printer\%20Friendly\%20Versions/APPROACHES\%20TO\%20EDUCATIONAL\%2 OPLANNING.pdf.

Ololube, N. P. (2004). Professionalism: An Institutional Approach to Teachers' Job Effectiveness in Nigerian Schools. Paper Presented at the Seventh International LLinE Conference, September 23-25, 2004.

Ololube, N. P. (2006). Teachers Job Satisfaction and Motivation for School Effectiveness: An Assessment, Essays in Education, 18, 1-19.

Ololube, N. P. (2006b). Teacher Education, School Effectiveness and Improvement: A Study of Academic and Professional Qualification on Teachers' Job Effectiveness in Nigerian Secondary Schools. Doctoral Dissertation, December 2006. University of Helsinki, Faculty of Behavioral Sciences, Department of Applied Sciences of Education, Helsinki: University of Helsinki Press.

Ololube, N. P. (2009). Understanding teachers professional competencies for education effectiveness. Owerri, Nigeria: SpringField Publishers.

Ololube, N. P. (2013). Educational management, Planning and Supervision: Models for Effective Implementation. Owerri, Nigeria: SpringField Publishers.

Ornstein, A. C., \& Levine, D. U. (2006). Foundations of Education (9th Ed.). New York, NY: Houghton Mifflin.

Peretomode, V. F. (1995). The general principle of school administration. In V. F. Peretomode (ed). Introductin to educational Administration, planning and supervision. Ikeja: Joja Press

Peretomode, V. F. (1991). Educational Administration: Applied concept and Theoretical Perspective. Lagos: Joja Educational Research and Publishers.

Peretomode, V. F. (Ed) (1995). Introduction to Educational Administration Planning and Supervision. Lagos: Joja Educational Research and Publishers.

Robertson, I. T. (1991). An Evaluation of Outdoor Development as a Management Development Tool. MBA Dissertation. University of Edinburgh.

Wali, W. I. (2002). Administration of Employee Welfare Programmes in Post Primary Institutions in Rivers State. Unpublished MED Thesis, University of Port Harcourt.

Wali, W. I. (2010). Delegated functions and the legal implications of the principles of vicarious liability in school administration. Trends in Educational Studies, 1(2), 68-78.

Wali, W. I., \& Elekwa, J. E. (2012). Cost-effective Employee Appreciation Strategies in Schools: A Review of Literature. International Journal of Scientific Research in Education, 5(3), 190-196.

Wall, S. J., \& Wall, S. R. (1995). The evolution (not the death) of strategy. Organizational Dynamics, 24(2).

Whawo, D. D. (1993). Educational Administration, planning and supervision. Benin City: Jodah Publications.

Willis, S. L., \& Dubin, S. S. (Eds) (1990). Maintaining Professional Competence. San Franicsco: Jossey-Bass Publishers. 